\title{
SÕNA
}

\section{VAGEL: KAS ETÜMOLOOGILINE UMBSÕLM?}

\author{
LEMBIT VABA
}

$\mathrm{S}$ õna vagel päritolu on eesti etümoloogiasõnaraamatute (EEW; EKET) andmeil ebaselge. Soome etümoloogide katsed osutada ee vagel vanaks germaani laenuks on ebaõnnestunud. Kas tõesti on tegemist etümoloogilise umbsõlmega?

vagel : vagla : ‘vakla 'ussike, tõuk' on lõunaeestiline (Kask 1984: 206), kuid tänapäeval hästi tuntud ka põhjaeestilises ühis- ja kirjakeeles. Teistes läänemeresoome keeltes pole vastet tuvastatud. „Eesti keele seletav sõnaraamat” esitleb kõnealust sõna nii: „... paljude kahetiivaliste peata ja jalgadeta vastne, ussike, tõuk. Kärbeste vaglad. Kahjurite munadest koorunud vaglad kahjustavad taimi. Mesilaste haudmes on munad, vaglad ja nukud. Mädanevasse haava tulid 'tekkisid' valged vaglad. Vaklu täis korjus" (EKSS 6: 110). Käesolevast sõnaloost selgub, et vagel on põhjaeestilises keelepruugis juba ammu olnud kasutusel mesindussõnana, tõik, mille toob esile ka EKSS-i näitematerjal. Tänapäeva eesti kirjakeeles on vagel leidnud rakendust paljude oskussõnade loomisel, näiteks vagel/lest 'mikroskoopiline usjas nugiline inimese karvanääpsu rasunäärmeis, nääpsulest (Demodex folliculorum)' (EKSS 6: 110), vagel/ebaheinik (Lepista personata (Fr.) Cooke).

Lõunaeesti vagel : vagla : 'vakla, vagõl'/vagul': vagla, vakl : vagla/vaala1 tähendusväli jaguneb EKI murdekataloogi andmeil laias laastus kolmeks: 1. 'ussike, tõuk, (vihma-, kapsa-, seene)uss, kooreürask' (nt TMr Võn Kam Ote San Kan Urv Krl Har Rõu Plv Vas Se Kra); 2. 'kiinimuhk, s.o. kiini vastse muhk looma naha all' (nt Hää Trv Pst Hls Krk Hel Rõn Har Rõu Plv; ku lihm talvõl põhku süü, sis omma keväjelt vagla naha alh Har); 3. 'vinn, vistrik' (Se Lei); tähendus 'puukäsn' (Trv) on ilmselt juhuslikku laadi, johtudes tõenäoliselt segiminekust häälikuehituselt lähedase sõnaga tagel : tagla 'tael'. Eraldi tuleks veel esile tõsta järgmisi kitsamalt tuntud spetsiifilisi tähendusi: 'mesilasvastne' (Rõn Räp), 'kõhu- uss' (San), 'toonesepp' (Vas: kui vagel saina seeh tsaga vai järä, niigu mõni taskuuur, sis säält majast kiäki ärä kuolma saago) ja 'vaenuköis' (Lut vaglakõnõ)'. Andrus (Albert) Saareste on esitanud lõunaeestilise sõna vagõl/vakl vihmaussinimetuste hulgas, rõhutades: „Paiguti ei näi rahvas vihmaussi tõukudest ega mardikaist nime poolest eraldavatki.” Veel on Saareste arvanud, et eesti vihmaussinimetusi tuleb pidada „võrdlemisi vastseks” ja nende hulgas ei leidu ainustki, „mis samas tähenduses põlvneks kindlasti algsoomest" (Saareste 1924: 76-77).

${ }^{1}$ Murdenäited on siin ja edaspidi esitatud valdavalt kirjakeele vahenditega. 
Eesti keele mõisteline sõnaraamat esitab sõna kohta järgmist: vagel: vagla 'tõuk' (IdMlg KaE) (EKMS III: 270 sub Putukad); vagel : vagla 'tõuk, ussike (LE), kärbse vaste (EE): kapsa-v[agel], tuli-v[agel] 'jaaniussike', kapsa ussid, aga liha ja looma $v[$ agla]d (SanV); looma naha all on $v$ [agel], kõik muud tõugud on meil ussid (PstT), vagel/tang 'plerocercoid, paelusside teatud arengujärk' (EKMS IV: 257-258 sub Uss). VES toob järgmised häälikuvariandid ja tähendused: vagõl, vagyl', vakl 'tõuk, ussike, vagel' (VES: 509).

vagel tuleb ootuspäraselt esile lõunaeesti regilauludes ja muus folkloorses materjalis, sh vanasõnades: Kan täi su täko söönu,/kirbu su kiriva ruuna,/ vagla so valge hobese! (ERL III/2: 468; üleskirjutus aastast 1889); Trv Kõhna vaska om ikki vaklan (EV I: 868); Se Tuu olõ õi vagõl, mia esi ar' sü̈̈t, tuu om suur, mis hindä ar' sü̈̈ (EV III: 575).

Lõunaeestilise sõna vagel ja sellest tuletatud verbe registreerivad eesti vanemad leksikograafilised allikad: Made Waggal/a; (Gutslaff 1648); Waggel, ein Wurm (Vestring 1998: 356); waggel, gla Wurm, Made d., waglakenne ein Würmchen, Raupe d., waglatu (od. ärrawaglatu) pu wurmstichig Holz d. (Hupel 1780: 302); waggel, gla Wurm, Made d., waglakenne Würmchen; Raupe d., waglama, waglatama wurmstichig machen d., sup[inum] p[assiv] waglatu wurmstichig (Hupel 1818: 272), wurmstichig ussitand r., (ärrä) wagglatetu od. waglatu d. (Hupel 1818: 629); wagl G. wagla (pt, d), dimin. waglakene G. waglakeze 'uss, vagel, tõuk, röövik/Wurm, Made, Raupe', kapsta-w. 'Kohlraupe', tuli-w. 'Leuchtwurm (Lampyris noctiluca)', rõngas-w. 'Ringelraupe', tuhk-w. 'Blattlaus', waglama (d), waglatama (d), wakluma (d) 'wurmstichig werden, voll Würmer, Maden, werden', waglutama (d) 'wurmstichig, voll Würmer oder Maden, machen' (Wiedemann 1973: 1284, 1294).

vagel esineb XVII sajandi lõunaeestikeelsetes piiblitõlgetes, Johannes Gutslaffi tõlgitud Vanas Testamendis (VT) ja 1686. aastal ilmunud, peamiselt Andreas ja Adrian Virginiuse tõlgitud Wastses Testamendis (WT): Nemmat enge is wötta Moseh sönna mitte; enge mönne mehet jetsit temmast ülle, hohmeni, sihs kaswasit waggalat sähl sissen, ninck se haisus kurjaste [VT 2Ms16:20]; Sihs pannit nemmat tallalle hohmeni, ni kui Moseh kescknut olli, Ninck se is haisu üsseki kurjaste, is sah ka waggalat mitte sisse [VT 2Ms16:24]; Kun neide Waggel ei kohle/nink Tulli erra ei kisto [WT Mk9:44]; Kun neide Waggel ei kohle/nink Tulli erra ei kisto. [WT Mk9:46]; Kun neide Waggel ei kohle/nink Tulli erra ei kistos [WT Mk9:48] (http://www.eki.ee/piibel).

On tähelepanuväärne, et sõna waglad esineb Anton Thor Helle muidu läbinisti põhjaeestikeelses mesilaspidamise õpetuses („Neist messilastest Von Bienen”), puudub aga väljaande sõnastikuosas: Kui ta löppetab poiad kandmast, siis wottab talluda seält seest neid waglad kerre seest wälja, lessed kissuwad nemmad ärra. Wenn sie aufhören junge zu zeugen, so tragen sie das unreine aus den Fächern hinaus und tödten die Threnen (Helle 1732: 401). Friedrich Wilhelm v. Willmanni „Juttude ja Teggude” (1782) mesilaspidamise õpetus („Öppetus kuida keik ma rahwas woib, ilma sure waewata, linnopuud piddada, ja se läbbi rikkaks saada”) toetub mõnes osas Thor Helle tekstile (vt Vinkel 1975: 247), kuid Willmannil puudub tekstiosa, kus esineks waglad. Anton Knüpfferi (1817: 128) teatel leidub waglad 'Bienenbrut [= mesilashaue]' koguni Heinrich Gösekenil.

Peaaegu kõik läänemeresoome sõnad, milles esineb resp. on esinenud *kljärjend, on osutatud laentüvedeks: vanadeks balti laenudeks kael (< vlms 
*kakla < blt *kakla /* kaklan) ja tael (< vlms *takla < blt *dagl'a-), vanadeks germaani laenudeks aga nt nael, nõel, sõel ja tõenäoliselt ka pael. Silbilõpulise klusiili vokaalistumine on vana erijoon (vt nt Saareste 2006: 104), milles uuemad laenud (saksa, vene, läti, rootsi) ei ole osalenud (nt taglas < sks, aglets 'teat. kaerasort' < vn, pegla 'peru (hobune), edev (inimene)' < vn, niglas jt. 'väike söödakala jt.' ? < lt, $\operatorname{kagl}(a)$ 'lagle' < erts; ohtralt gl- ja gr-järjendiga uuslaene on Kodavere murdekeelest toonud L. Kettunen (1913: 124). Silbilõpuline velaarpalataalklusiil $* k$ on läänemeresoome keeltes jäänud püsima lõunaeesti, liivi, vadja, idasoome, isuri, karjala ja vepsa keeles (vt Laanest 1975: 67-68). Põhjaeesti murdealal, rannikumurdes ja soome kirja- ning läänesoome murdekeeles * $k$ nõrgenes ja vokaalistus (Rätsep 1989: 1507): põhjaeesti murdeis ${ }^{*} \gamma>i>e\left(\right.$ kail $>$ kael), ranniku- ja läänesoome murdes ${ }^{*} \gamma>u$ $[\operatorname{kaul}(a)]$, mis on arvukate juhtudega esindatud ka idamurde alal Kodaveres ja mujalgi, eriti rohkesti rannikumurdepärasusi leidub Iisaku murrakus (Must 1987: 72; Univere 1996: 11, 14).

Vlms * $k l$-järjendi jätkajad mõnes balti ja germaani päritolu tüves [vt ka VEM: 45 (kaart 41: kael, kaer, nael)]:

\begin{tabular}{|c|c|c|c|c|}
\hline $\begin{array}{l}\text { XVI-XVII sa- } \\
\text { jandi } \\
\text { põhjaeesti } \\
\text { kirjakeel }\end{array}$ & $\begin{array}{l}\text { põhjaeesti } \\
\text { murde- } \\
\text { ja/või kirja- } \\
\text { ja ühiskeel }\end{array}$ & $\begin{array}{l}\text { rannikumurre } \\
\text { /idamurre }\end{array}$ & $\begin{array}{l}\text { lõunaeesti } \\
\text { murdekeel }^{*}\end{array}$ & $\begin{array}{l}\text { soome lääne- } \\
\text { murded } \\
\text { ja kirjakeel }\end{array}$ \\
\hline $\begin{array}{l}\text { kail } \\
\text { tail } \\
\text { nail } \\
\text { nõol } \\
\text { sõõl } \\
\text { pail }\end{array}$ & $\begin{array}{l}\text { kael/ kaal } \\
\text { tael/taal } \\
\text { nael/naal } \\
\text { nõel/nõõl } \\
\text { sõel/sõol } \\
\text { pael/paal } \\
\text { vael }\end{array}$ & $\begin{array}{l}\operatorname{kaul}(a) / \mathrm{kaa} \\
\operatorname{taul}(a) / \operatorname{taal} \\
\operatorname{naul}(a) / \operatorname{naal} \\
\operatorname{neul}(a) \text { nõkl, } \\
\operatorname{seul}(a) \text { sõkl, } \\
\operatorname{paul}(\text { a)/paal } \\
\text { vaul/vaal }\end{array}$ & $\begin{array}{l}\text { kakl, kagõl jt } \\
\text { takl, tagõl jt } \\
\text { nakl, nagõl jt } \\
\text { nõgõl jt } \\
\text { sõgõl jt } \\
\text { pakl, pagõl jt } \\
\text { vakl, vagõl jt }\end{array}$ & $\begin{array}{l}\text { kaula } \\
\text { taula } \\
\text { naula } \\
\text { neula } \\
\text { seula } \\
\text { paula }\end{array}$ \\
\hline
\end{tabular}

\section{Juhan Liivi mõttesalmi vael 'veisekiini vastne'}

Juhan Liivi loomingule on Kodavere kodumurde keelendite kasutamine üsna iseloomulik (vt nt Saareste 2006: 265). Sisuldasa kontekstiga hästi lõimuv vael (vaelad on veiste nuhtlus!) esineb Liivi 1908. aastaga dateeritud killus ehk mõttesalmis, mille esmapublikatsioon pärineb aastast 1919: Mees pole pikem kübarast, / härg viimsest vaelast raskem, / ei rahvus parem rahvusest; / mis on nad - olla laskem! (Liiv 1919: 67; samuti 1926: 265; 1964: 52). Ent enamik Liivi luule Teise maailmasõja järgseid väljaandjaid ja toimetajaid on neile arusaamatu vaela väänanud naelaks (Liiv 1954: 431; 1956: 431; 1969: 160; 1989: 326; 2010: 120 jt): ... härg viimsest naelast raskem, ... Leksikograafilised allikad kõnealust häälikukuju vael ei registreeri. Ometi on vael *kl-sõnade ootuspärane põhjaeesti keskmurde vokaliseerunud häälikukuju: Kodaveres ja mujalgi idamurdes on ${ }^{*} k l$-sõnade rannikumurdepäraste $u$-diftongiliste häälikukujude kõrval (nt Kod sõul : sõõla, 'sõula 'sõel', 'nõul : nõ̃̃la 'nõel', vt Kettunen 1913: 123; 1914: 39; Univere 1996: 216, 229) ka assimileerunud (Kod naal

\footnotetext{
* Tänan Väino Klausi märkuste eest lõunaeesti keelenäidete tõlgendamisel.
} 
: 'naala 'nael', kaal : kaala 'kael', nõõlaga, paal 'pael', vt Kettunen 1913: 84, 123; 1914: 32-34, 103-105; Univere 1996: 210, 228, 291) ja tüüpilisi keskmurdelisi (nt Kod tael: taèl one nĕ̌nnaGu sîñ. meńi kutsub täDä taèl. menni kutsub pes, vt Univere 1996: 201) ja lõunaeestilisi (Kod sgg. nagli 'varn', lõunaeesti laenuks on seda pidanud Kettunen 1913: 124; vt ka Univere 1996: 263). Erisuunaliste mõjude virvarr iseloomustab ka analüüsitavat sõna.

vaul/vaal/vual/voul/vaun/vouv 'kiinitõuk, -muhk looma naha all, õieti veisekiini vastne'

Need suhteliselt haruldased ranniku- ja idamurdelised häälikuvariandid ei ole etümoloogilise uurimise vaatevälja pääsenud. Varasem leksikograafia, sh Wiedemanni sõnaraamat neid ei registreeri. Kõnealustel häälikuvariantidel on otsustav osa käesoleva etümoloogilise umbsõlme lahtiharutamisel. Mari Must (1987: 73) on küll möödaminnes ettevaatlikult oletanud, et vaul jt esindavad ilmselt samuti silbilõpulise klusiili vokaalistumise juhte, ja lisanud võrdluseks lõunaeesti vagel, vakl. Alljärgnevalt on esitatud kõnealuste häälikuvariantide täpsem levila: vaal (MMg), vual, -u: lehmäl vualud sel'jä luu juuren; ühe vualu vajotasin väl'jä (Lai Kod) (IMS: 246); vaulad pl (Iis) IMS: 252, vuul : vualu: mõjal ei tiä vuùla õlema ku lehmädel sel'jä siden (Kod) IMS: 261.

Eesti keele mõistelises sõnaraamatus leiduvad järgmised teated: vaal, $-u$ 'vagel, kiini tõuk veise naha all' (Kod MMg), vaun, -a (Al); vaul, - $a$ (Iis), voul, - $i$ (JõeVi, KiKuu, VNg), vouv, -i (Lüg) 'looma naha alla kiini munemisest tekkinud tõuk' (EKMS IV: 257-258 sub Uss); vaun, - a 'kiini tõuk looma ihus' (Al), vaal, -u 'kiini tõuk looma ihus' (Kod) (EKMS III: 270 sub Putukad). Idamurde ala iseloomustab ühelt poolt pika $\bar{a}$ püsimine (vaal), teiselt poolt aga diftongistumine $(\bar{a}>o a>u a$ : vual). A. Univere (1996: 13) peab pika $\bar{a}$ püsimist lõunaeestipäraseks murdejooneks ja L. Kettunengi (1914: 34) kaldub arvama sama. vuul-variandi kõrgenenud pikk $\bar{o}$ on inspireeritud vahest sõnast vool 'vigastus puul' (selle idamurde sõna kohta vt IMS: 261). Tähelepanu äratab tüvevokaali vaheldus. Deetümologiseerunud kujud on vaun ja vouv: vaun on häälikuliselt ilmselt mõjustatud sõnast vaenuköis ('vaenusääse rändavate vaklade rida'), vouv aga vahest sõnadest vaev ja/või väiv 'looma-, naha- või karvatäi; ting'.

\section{vagel on balti laen}

Julius Mägiste (EEW XI: 3628) sõnale etümoloogiat esitanud ei ole, varasemates käsitlustes oletatud seost sm vaula-sõnaga pole ta ootuspäraselt samuti maininud ja Alo Raun (EKET: 195) on nentinud, et sõna päritolu on ebaselge.

Oletatav balti lähtekuju on *vagVlja-/*vagulja-, mille jätkaja tänapäeva balti keeleruumis on läti murrete vagul(i)s, vaguol(i)s 'mardikas, sitikas, põrnikas/ein Käfer, der Baumkäfer', vaguols 'väike must mardikas/ein kleiner, schwarzer Käfer', vagules pl 'jahus elutsevad väikesed mustad putukad/kleine, schwarze Insekten im Mehl', sūdu vabule ir vagulis 'sitasitikas on vagulis', uz kāpuostiem dzīvuo mazi (mælni) vagulīši 'kapsastel elutsevad väikesed (mustad) putukad', labības vagulis [mingi teraviljakahjur (nisukahjur)]' (ME IV: 432: vagulis; EH II: 747: vaguls), ülemlt (seeli Dignāja) vogūl's/ vo:gùl's, vogūla 'par vagoliem sauc dažādas nelielas, kustīgas vaboles/v-teks 
kutsutakse mitmesuguseid väikesi kärmelt liikuvaid mardikaid' (Indāne 1986: 190), (latgali Kalupe) vogûls 'mittelendav (nt mardikaliste seltsi kuuluv) putukas/nelidojošs (piemēram, vaboḷu kārtas) kukainis' (Rek̦ēna 1998: 533), (Tilža) vogùls ['putukas'], iûd'iṇa voguty ['? sääsevastsed'] (Üsele 1998: 73); sõna esineb ka dainakeeles: Es orojs kai úzuls,/Kumeleņš kai voguls 'Mina künnimees kui tamm/Hobu [ees] kui põrnikas' (Ludza) (www.dainuskapis.lv). Läti leksikograafilistest allikatest ja murdeülevaadetest nähtub, et sõna vaguls jne leviku tuumala hõlmab ülemläti ja sellega külgnevad keskläti murded. Tänapäeva läti kirjakeel on teinud sõna tuntuks kogu läti keelealal. Läti vagu(o)lis jt on ilmselt sekundaarareng tüvest vabu(o)l-. Jānis Endzelīns on nimelt oletanud (1924: $119^{2}$; 1936; 24; nii ka LEW II: 1176; LEV II, 462), et vagu(o)l-on dissimilatiivne kuju tüvest vabal-/vabu(o)l, s.o $v-b$ $>v-g$. vabal-/vabu(o)l-tüvelised nimisõnad on esindatud nii leedu kui ka läti keeles: ld vãbalas, vãbuolas, vãbolè '(sita)sitikas, põrnikas/(Mist)- käfer', lt vabuole, vabuol(i)s, vabule, vabul(i)s, vabala, vabale, vabals, vabele ${ }^{2}$ 'sitasitikas, maipõrnikas, seitsetäpp-lepatriinu/Mistkäfer (Geotrupes stercorarius L.), Maikäfer, Sonnenkälbchen (Coccinella septempunctata)' (ME IV: 428; LEW II: 1176). Mõlemad balti tüvevariandid on morfoloogiliselt liitsed, sisaldades vanapärase tuletusliite elementi - $l$ - (asjaomaste liitesarja kohta lähemalt vt Endzelīns 1951: 340 jj). Balti laenudest on tael samamoodi $l$-liiteline substantiiv (blt *dag- + *-la-). -l- võib liituda nii vokaal- kui ka konsonanttüvele. Paljud kõnealust tuletusliite elementi sisaldavad deverbaalsed $u l$-tuletised on läti keeles vanad või väga vanad (MLLVG I: 155-157 jj). Läti kirjakeele kontekstis on vabole [loe: vabuole], vagulis ja vambale (viimase kohta vt täpsemalt joonealuses) sünonüümid (LVSV: 440). Selle balti mardikanimetuse indoeuroopa arhetüüp on *uebh- 'siia-sinna liikuma, kihama; siduma, punuma, kuduma/ sich hin und her bewegen, wabern, wimmeln; weben, flechten, knüpfen', mille jätkajaks on balti keeltes *ueb-tüvi: sõnaperre kuuluvad lisaks eeltoodule nt ld vebžd'éti 'kubisema, kihama/wimmeln, sich verwirren, durcheinander bewegen', vabzdỹs 'putukas, kahjurputukas/Insekt, Ungeziefer', lt vebzis 'üleannetu, vallatu, jonnakas laps, võrukael/nerātns, niķīgs bērns' (vt IEW II: 1114-1115; LEV II: 462); balti sõnaperega kaugemas suguluses on vn murd веблииа 'tõuk, vagel, põrnikas; (sooltes, lihastes, ajus elutsev) loomaparasiit (= нутряк)' (ESRJa I: 282; SRNG 4: 89). Olgu märgitud, et vaadeldava indoeuroopa sõnaperega on seotud veel algblt *vapsā (ld vapsà, vãpsas 'herilane, parm/Wespe, Bremse', vapsvà 'herilane/ Wespe', lt murd vapsene, vapsine id., mpr wobse id. (IEW II: 1179; LEW II: 1196-1197; LEV I: 501: lapsene), mis on vlms *vaps(a)- 'herilane (Vespa vulgaris), vapsik (Vespa crabro) jt ' laenualus: ee vapsik jt, lvS vapški, K vap̄s, vdj vāpsaz jt, sm vapsahainen, is vaapsainen $\mathrm{jt}$, krj voapšaha(i)ńe $\mathrm{jt}$, lü vuapsahaine jt, vps bapshaine jt.

\footnotetext{
2 Sellest tüvevariandist pärinevad liivi keele läti hilislaenud lvS vābil 'kahjurputukas / Ungeziefer', šita vābil 'sitasitikas / Mistkäfer', K vabil' 'lepatriinu / Marienkäfer' (LW: 463b). Läti nasaalsest tüvevariandist vambale jt 'mardikas, põrnikas, sitasitikas; rammus noorloom, lihav laps' on ilmselt inspireeritud Plv Vas vamblanõ 'üleannetu, ülemeelik, kelm inimene; vaenlane (sõimusõnana)' $\leftarrow$ 'kiiresti siia-sinna liikuv ja ettearvamatult suunda muutev', vrd nt põrnikas 'väike (terane, elav) laps (hrl poisi kohta)' (EKSS 4), murd massakas 'putukas; rüblik' (VMS II).
} 


\section{Lõunaeesti vagel ja soome vaula?}

E. N. Setälä (1890-1891: 139) ja E. Nieminen (1934: 38) on sidunud lõunaeesti sõna vagel : vagla ja eelkõige soome läänemurdes, aga ka mujal tuntud sõnaga vaula / vaulo / vaulu / vaunu 'vitsavõru; vitsavõrust tehtud jalasepidur; võrgunöör/vitsalenkki; vitsarenkaasta tehty jarrulaite jalaksessa; (Jusl.) nuotan paula' ning päriskrj vaunu 'vitsavõru/vitsalenkki', lp vyevli, vevli '(koera, lehma) kaelarihm/(koiran, lehmän) kaulain', mis on vormiliselt mõeldav, kuid semantilistel põhjustel täiesti ebausutav. Selle kõrvutuse on tõrjunud ka Károly Rédei (UEW I/5 1988: 553). J. Koivulehto (1976: 258-259) on kõnealusele sm-krj sõnale esitanud germaani etümoloogia (vlms *vakla $<(\mathrm{v})$ alggerm *waðla-/*watla-, kus dentaali ja $l$-i ühend korvati *kl-ga) ja arvanud, et ee vagel sobiks häälikuliselt sellesse sõnaperesse ja semantiliseltki poleks ühendamine võimatu, esitades oma mõtte toeks näite rootsi keele Gotlandi murdekeelest, kus tain 'värten' on saanud lisatähenduse 'angerjas' (< germ *tai$n a$ - 'vits, oks'). Soome keele etümoloogiasõnaraamatud aktsepteerivad J. Koivulehto germaani etümoloogia, kuid ei seo ootuspäraselt ja õigustatult selle ja eesti esinemust (vt SKES VI: 1679; SSA 3: 420). Tõenäoliselt kuulub sm vaula-sõnaga samasse sõnaperesse ka seni etümoloogide vaateväljast kõrvale jäänud päriskarjala (Kontokki) itkude vaklo-: vaklo/nimyt'laubarätt (kui neiupõlve tunnus) ottšapaikka) (tyttöyden tunnusmerkkinä)' (http://kaino.kotus.fi / cgi-bin / kks / karjala.cgi? $a=$ vaklonimyt\&l=1), kus ootuspäraselt püsib karjala keelele tüüpiline silbilõpu klusiil.

Kokkuvõtvalt võib tõdeda järgmist: lõunaeesti taustaga vagel ja selle põhjaeestilised ning rannikumurdelised häälikuvasted osutavad, et tegemist on * $k l$-sõnaga. Need ja teised kuuluvad balti vastete suhteliselt kitsast levikust hoolimata balti laenude vanemasse kihistisse. Seda oletust toetavad häälikuseigad. Taas kord leiab kinnitust tõsiasi, et sõna levik on sõna vanuse tuvastamisel küllalt ebakindel kriteerium.

\section{Kirjandus}

EEW I-XII = Julius Mägiste, Estnisches etymologisches Wörterbuch I-XII. Helsinki: Finnisch-Ugrische Gesellschaft, 2000.

EH = Jānis Endzelīns, Edite Hauzenberga, Papildinājumi un labojumi K. Mülenbacha Latviešu valodas vārdnīcai I-II. Rīgā Grāmatu apgāds, 1934-1946.

EKET = Alo Raun, Eesti keele etümoloogiline teatmik. Rooma-Toronto: Maarjamaa, 1982.

EKMS I-IV = Andrus Saareste, Eesti keele mõisteline sõnaraamat I-IV. Stockholm: Vaba Eesti, 1958-1963.

EKSS = Eesti keele seletav sõnaraamat 1-6. „Eesti kirjakeele seletussõnaraamatu” 2., täiendatud ja parandatud trükk. Toim M. Langemets, M. Tiits, T. Valdre, L. Veskis, Ü. Viks, P. Päll. Tallinn: Eesti Keele Sihtasutus, 2009.

E n d z e l i n, Jānis 1924. Germanisch-baltische Miszellen. - Zeitschrift für vergleichende Sprachforschung auf dem Gebiete der indogermanischen Sprachen, lk 110-128.

E n d z e līn s, Jānis 1936. Sīkumi CLXVIII. - Filologu biedrības raksti 16. Rīgā, lk 24. 
Endzelīns, Jānis 1951. Latviešu valodas gramatika. Rīgā: Latvijas valsts izdevniecība.

ERL III/2 = Eesti rahvalaulud. Antoloogia. III: 2. [Toim. Ülo Tedre]. Tallinn: Eesti Raamat, 1971.

ESRJa I = Макс Фасмер, Этимологический словарь русского языка I. Перевод с немецкого и дополнения О. Н. Трубачева. Москва: Прогресс, 1964.

EV I, III = Eesti vanasõnad I, III. Toim A. Krikmann, I. Sarv. Tallinn: Eesti Raamat, 1980, 1985.

Guts laff, Johannes 1648. Observationes grammaticae circa linguam Esthonicam. Dorpati Livonorum: Excudebat Johannes Vogel/Acad. Typogr. Anno M DC XL VIII.

Hell e, Anton Thor 1732. Kurtzgefaßte Anweisung Zur Ehstnischen Sprache. Vt ka: Lühike sissejuhatus eesti keelde 1732. Saksa keelest tõlkinud ja järelsõnad kirjutanud Annika Kilgi, Kristiina Ross. Tallinn: Eesti Keele Sihtasutus, 2006.

H u p e l, August Wilhelm 1780. Ehstnische Sprachlehre für beide Hauptdialekte den revalschen und den dörptschen; nebst einem vollständigen Wörterbuch. Herausgegeben von August Wilhelm Hupel. Riga und Leipzig, bey Johann Friedrich Hartknoch (vt ka: http://www.utlib.ee/ekollekt/eeva).

H u p e l, August Wilhelm 1818. Ehstnische Sprachlehre für die beyden Hauptdialekte, den revalschen und dörptschen, nebst einem vollständigen ehstnischen Wörterbuche. Zweyte durchgängig verbesserte und vermehrte Auflage. Mitau.

IEW II = Julius Pokorny, Indogermanisches etymologisches Wörterbuch. Bern: A. Francke AG. Verlag, 1953.

IMS = Valdek Pall, Idamurde sõnastik. Tallinn: Eesti Keele Instituut, 1994.

I n d ā n e, Irma 1986. Dignājas izloksne. Rìgā: Zinātne.

K a s k, Arnold 1984. Eesti kirjakeele sõnavara murdelisest taustast. - Eesti murded ja kirjakeel. (Emakeele Seltsi toimetised 16.) Tallinn: Valgus, lk 201-209.

Kettunen, Lauri 1913. Lautgeschichtliche Untersuchung über den kodaferschen Dialekt. (Suomalais-ugrilaisen Seuran toimituksia XXXIII.) Helsinki: Suomalais-Ugrilainen Seura.

Ke t t u n e n, Lauri 1914. Lautgeschichtliche Darstellung über den Vokalismus des kodaferschen Dialekts mit Berücksichtigung anderer estnischen Mundarten. (Suomalais-ugrilaisen Seuran toimituksia XXXIV.) Helsinki: Suomalais-Ugrilainen Seura.

Ko iv u le hto, Jorma 1976. Vanhimmista germaanisista lainakosketuksista ja niiden ikäämisestä II. - Virittäjä, lk 247-290.

$\mathrm{K} \mathrm{n} \ddot{\mathrm{u}} \mathrm{pff}$ e r, Anton 1817. II. Wörter und Redensarten, die in Hupels Wörterbuche nicht stehen. Funfzehnter Beitrag. - Beiträge zur genauern Kenntniss der esthnischen Sprache III/9. Hrsg. von Joh. Heinr. Rosenplänter. Pernau, lk 33141.

L a a n e st, Arvo 1975. Sissejuhatus läänemeresoome keeltesse. Tallinn: Eesti NSV TA Keele ja Kirjanduse Instituut.

LEV I-II = Konstantīns Karulis, Latviešu etimoloǵijas vārdnīca. Rīga: Avots, 1992.

LEW II = Ernst Fraenkel, Litauisches etymologisches Wörterbuch II. Heidelberg: Carl Winter Universitätsverlag, Göttingen: Vandenhoeck \& Ruprecht, 1965.

L i i v, Juhan 1919. Juhan Liivi luuletused. Kolmas, täiendatud ja parandatud trükk. „Noor-Eesti Kirjastus” Tartus.

L i i v, Juhan 1926. Juhan Liivi luuletused. Neljas, täiendatud trükk. „Noor-Eesti Kirjastus" Tartus. 
L i i v, Juhan 1954. Teosed. Proosa. Luule. Tallinn: Eesti Riiklik Kirjastus.

L i i v, Juhan 1956. Teosed. Proosa. Luule. Tallinn: Eesti Riiklik Kirjastus.

Li i v, Juhan 1964. Rukkivihud rehe all. Valimik luuletusi. Koost P. Rummo. Tallinn: Eesti Riiklik Kirjastus.

L i i v, Juhan 1969. Luuletused. Tallinn: Eesti Raamat.

L i i v, Juhan 1989. Sinuga ja sinuta. Koost A. Vinkel. Tallinn: Eesti Raamat.

L i i v, Juhan 2010. Oh, elul ikka tera on. Mõttesalmid. „Killud”. Koost J. Talvet. Tallinn: Tänapäev.

LVSV = Latviešu valodas sinonīmu vārdnīca. 3. papildinātais un pārstrādātais izdevums. [Rīga:] Avots.

LW = Lauri Kettunen, Livisches Wörterbuch mit grammatischer Einleitung. (Lexica Societatis Fenno-Ugricae V.) Helsinki: Suomalais-Ugrilainen Seura 1938.

ME IV = K. Mülenbacha Latviešu valodas vārdnīca I-IV. Rediǵējis, papildinājis, nobeidzis J. Endzelīns. Rīgā: Kultūras fonda izdevums, 1929-1932.

MLLVG I = Mūsdienu latviešu literārās valodas gramatika I. Fonētika un morfologija. Rīgā: Latvijas PSR Zinātṇu Akadēmijas izdevniecība, 1959.

M u st, Mari 1987. Kirderannikumurre. Häälikuline ja grammatiline ülevaade. Tallinn: Valgus.

$\mathrm{N}$ i e $\mathrm{m}$ i $\mathrm{n}$ e n, Eino 1934. Der stammauslaut der ins urfinnische entlehnten baltischen $\bar{a}$-feminina und die herkunftsfrage. - Finnisch-Ugrische Forschungen XXII, nr 1-3, lk 5-66.

R e k̦ è n a, Antoṇina 1998. Kalupes izloksnes vārdnīca. 2. sējums. Rīga: Latviešu valodas institūts.

R ät s e p, Huno 1989. Eesti keele tekkimise lugu. - Akadeemia, nr 7, lk 1503-1524.

$\mathrm{S}$ a a r e s t e, Albert 1924. Leksikaalseist vahekordadest eesti murretes I. Analüüs 60 kaardi ja 1 skeemiga. (ACUT(D), VI 1 .) Tartu: Kirjastus-Ühisus „Postimehe” trükk.

S a a r e s t e, Andrus 2006. Kaunis emakeel. Vaateid eesti keele elust-olust. Näiteid eesti keelest ja meelest 1524-1958. Tallinn: Eesti Keele Sihtasutus.

S e tälä, Eemil Nestor 1890-1891. Yhteissuomalainen äännehistoria. Helsinki: Suomalaisen Kirjallisuuden Seura.

SKES VI = Erkki Itkonen, Joki J. Aulis, Reino Peltola, Suomen kielen etymologinen sanakirja I-VII. (Lexica Societatis Fenno-Ugricae XII.) Helsinki: Suomalais-Ugrilainen Seura, 1978.

SRNG = Словарь русских народных говоров 4. Ленинград: Наука, 1969.

SSA 3 = Suomen sanojen alkuperä. Etymologinen sanakirja 3. (Suomalaisen Kirjallisuuden Seuran toimituksia 556. Kotimaisten kielten tutkimuskeskuksen julkaisuja 62.) Helsinki: Suomalaisen Kirjallisuuden Seura, Kotimaisten Kielten Tutkimuskeskus, 2000.

UEW I/5 = Károly Rédei, Uralisches etymologisches Wörterbuch I/5. Uralische und finnisch-ugrische Schicht. Budapest: Akadémiai Kiadó, 1988.

U n i v e r e, Aili 1996. Idamurde tekstid. (Eesti murded IV.) Tallinn: Eesti Teaduste Akadeemia Eesti Keele Instituut.

Ūs e le, Veneranda 1998. Tilžas izloksnes apraksts. Rīga: Latviešu valodas institūts.

VEM = Andrus Saareste, Petit atlas des parlers Estoniens. Väike eesti murdeatlas. (Skrifter utgivna av Kungl. Gustav Adolfs Akademien Nr 28.) Uppsala, 1955.

VES = Võro-eesti synaraamat. Võru-eesti sõnaraamat. Koost. Sulev Iva. (Võru Instituudi toimetised 12.) Tartu-Võru: Võro Instituut, 2002. 
Vestring, Salomo Heinrich 1998. Lexicon Esthonico Germanicum. Tartu: Eesti Kirjandusmuuseum.

Vi n k e l, Aarne 1975. Fr. W. Willmann ning tema „Juttud ja Teggud” - Friedrich Wilhelm Willmanni Juttud ja Teggud. - Loomingu Raamatukogu, nr 47-52. Tallinn: Perioodika, lk 245-253.

VMS II = Väike murdesõnastik II. Toim Valdek Pall. Tallinn: Valgus, 1989.

W i e d e m a n n, Ferdinand Johann 1973. Eesti-saksa sõnaraamat. Neljas, muutmata trükk teisest, Jakob Hurda redigeeritud väljaandest. Tallinn: Valgus.

\section{vagel - a Tricky Etymological Knot?}

Keywords: Finnic languages, Estonian, Baltic languages, etymology

The article considers the possible Baltic origin of vagel : vagla : 'vakla 'worm, larva', which has a South Estonian background, but is nowadays also used in the North-Estonian based common and standard language. The dialectal variants etymologically associated with the word vagel are vakl, vagõl, vaul/vaal/vual/ voul/vaun/vouv 'bot, swelling caused by gadfly maggots under animal skin'. Nearly all Finnic words currently or formerly containing the sequence * $k l$, have been proved to be borrowed stems, some of them being old Baltic loanwords like kael 'neck' (<*kakla), tael 'tinder' (<*takla), some old Germanic ones, e.g. nael 'nail', nõel 'needle', sõel 'sieve' and probably also pael 'ribbon'. Vocalization of the syllable-final stop occurring in the North Estonian dialect area, the Coastal dialect of Estonian, as well as in standard Finnish and western Finnish dialects is an old linguistic trait that does not concern more recent borrowings. Presumably the underlying Baltic form is *vagla-, surviving e.g. in Latv. dial. vagul(i)s, vaguol(i)s 'beetle/ein Käfer, der Baumkäfer', vaguols 'a small black beetle/ein kleiner, schwarzer Käfer', vagules pl 'meal beetles/kleine, schwarze Insekten im Mehl', Ltg. (Kalupe) vogûls 'flightless insect (possibly a Coleoptera)'. The Latvian vagu(o)l-is probably a dissimilative form of the stem vabal-/vabu(o)l-. The latter occurs both in Latvian and Lithuanian: Lith. vãbalas, vãbuolas, vãbole '(dung) beetle/ (Mist)käfer', Latv. vabuole, vabuol(i)s, vabule, vabul(i)s, vabala, vabale, vabals, vabele 'dung beetle, cockchafer, 7-spot ladybird/Mistkäfer (Geotrupes stercorarius L.), Maikäfer, Sonnenkälbchen (Coccinella septempunctata)'. Both Baltic stem variants are are morphologically complex, containing an element of the archaic affix $-l$-. In Latvian the $k l$-final derivatives containing the $l$-element are either old or very old. Some Finnish etymologists (Eemil Nestor Setälä, Eino Nieminen, Jorma Koivulehto) have tried associating the Estonian vagõl and Finnish vaula, -o, - $u$, also vaulu, vaulo, vaunu, Weidenrutenring; ein solcher Ring als Bremse an der Schlittenkufe', which is morphologically conceivable, but semantically totally unlikely. The idea is opposed, e.g. by Károly Rédei (UEW I/5 1988: 553). According to SKES VI: 1679; SSA 3: 420 vaula is a Germanic loanword, while no Estonian association is mentioned.

Lembit Vaba (b. 1945), PhD, lecturer in Estonian language and Culture at the University of Tampere, Assistant Professor at Tallinn University,

lembit.vaba@uta.fi 


\section{Tekstis kasutatud lühendeid}

Murded ja murrakud: Hargla; Helme; Hls = Halliste; Häädemeeste; Iisaku; Jõelähtme; K = keskmurre; Kambja; Kanepi, Kodavere; Kraasna; Krk = Karksi; Krl = Karula; Kuusalu; Laiuse; Leivu; Lutsi; Lüganuse; MMg = Maarja-Magdaleena (idamurre); Otepää; Plv = Põlva; Pst = Paistu; Rõngu; Rõuge; Räpina; Sangaste; Setu; TMr = Tartu-Maarja; Trv = Tarvastu; Urvaste; Vastseliina; VNg = Viru-Nigula; Võnnu.

Ke e l e d: blt $=$ balti; ee $=$ eesti; erts = eestirootsi; germ = germaani; is $=$ isuri; krj = karjala; ld = leedu; lp = lapi; lt = läti; lvS = Salatsi liivi; lü = lüüdi; $\mathbf{m p r}$ = muinaspreisi $; \mathbf{s k s}=$ saksa $; \mathbf{s m}=$ soome $; \mathbf{v d j}=$ vadja $;$ vlms = varajane läänemeresoome; vn = vene; vps $=$ vepsa. 